\title{
Article
}

\section{Loose Morphology and High Dynamism of OSER Structures Induced by the Membrane Domain of HMG-CoA Reductase}

\author{
Ricardo Enrique Grados-Torrez ${ }^{1,+}$, Carmen López-Iglesias ${ }^{2,3}$, Joan Carles Ferrer ${ }^{4}$ and Narciso Campos $1,4, * \mathbb{C}$ \\ 1 Centre for Research in Agricultural Genomics (CRAG) CSIC-IRTA-UAB-UB, Department of Molecular \\ Genetics, Campus UAB, Bellaterra (Cerdanyola del Vallès), 08193 Barcelona, Spain; regrados.old@umsa.bo \\ 2 Scientific and Technological Centers, University of Barcelona, 08028 Barcelona, Spain; \\ c.lopeziglesias@maastrichtuniversity.nl \\ 3 Microscopy CORE Lab, Maastricht Multimodal Molecular Imaging Institute, Maastricht University, \\ 6229 ER Maastricht, The Netherlands \\ 4 Department of Biochemistry and Molecular Biomedicine, Faculty of Biology, University of Barcelona, \\ 08028 Barcelona, Spain; jcferrer@ub.edu \\ * Correspondence: ncampos@ub.edu \\ † Present address: Facultad de Ciencias Farmacéuticas y Bioquímicas, Universidad Mayor de San Andrés, \\ Zona Miraflores 22-24, La Paz, Bolivia.
}

\section{check for} updates

Citation: Grados-Torrez, R.E.; López-Iglesias, C.; Ferrer, J.C.; Campos, N. Loose Morphology and High Dynamism of OSER Structures Induced by the Membrane Domain of HMG-CoA Reductase. Int. J. Mol. Sci. 2021, 22, 9132.

https://doi.org/10.3390/

ijms22179132

Academic Editor:

Masoud Jelokhani-Niaraki

Received: 18 July 2021

Accepted: 21 August 2021

Published: 24 August 2021

Publisher's Note: MDPI stays neutral with regard to jurisdictional claims in published maps and institutional affiliations.

Copyright: (c) 2021 by the authors. Licensee MDPI, Basel, Switzerland. This article is an open access article distributed under the terms and conditions of the Creative Commons Attribution (CC BY) license (https:/ / creativecommons.org/licenses/by/ $4.0 /)$.

\begin{abstract}
The membrane domain of eukaryotic HMG-CoA reductase (HMGR) has the conserved capacity to induce endoplasmic reticulum (ER) proliferation and membrane association into Organized Smooth Endoplasmic Reticulum (OSER) structures. These formations develop in response to overexpression of particular proteins, but also occur naturally in cells of the three eukaryotic kingdoms. Here, we characterize OSER structures induced by the membrane domain of Arabidopsis HMGR (1S domain). Immunochemical confocal and electron microscopy studies demonstrate that the 1S:GFP chimera co-localizes with high levels of endogenous HMGR in several ER compartments, such as the ER network, the nuclear envelope, the outer and internal membranes of HMGR vesicles and the OSER structures, which we name ER-HMGR domains. After high-pressure freezing, ER-HMGR domains show typical crystalloid, whorled and lamellar ultrastructural patterns, but with wide heterogeneous luminal spaces, indicating that the native OSER is looser and more flexible than previously reported. The formation of ER-HMGR domains is reversible. OSER structures grow by incorporation of ER membranes on their periphery and progressive compaction to the inside. The ER-HMGR domains are highly dynamic in their formation versus their disassembly, their variable spherical-ovoid shape, their fluctuating borders and their rapid intracellular movement, indicating that they are not mere ER membrane aggregates, but active components of the eukaryotic cell.
\end{abstract}

Keywords: HMG-CoA reductase; HMGR; HMGR vesicle; ER-HMGR domain; mevalonate; endoplasmic reticulum; OSER; high-pressure freezing; chemical fixation

\section{Introduction}

Eukaryotic HMG-CoA reductase (HMGR) has a key regulatory role in the mevalonate pathway for isoprenoid biosynthesis [1,2]. Isoprenoid products derived from this pathway are required for many diverse essential functions, including membrane biogenesis (sterols), control of growth and development (steroid hormones and plant cytokinins), protein prenylation (farnesyl and geranyl groups), protein glycosylation (dolichols) and respiration (ubiquinones) [3]. In plants, the mevalonate pathway also provides a wide variety of secondary metabolites required for defence against herbivores and pathogens or for the attraction of beneficial organisms [4]. In all plant species, HMGR is encoded by a multigene family. This was first proposed after analysis of few model plants [5], but has been confirmed by high throughput sequencing of an ever-increasing number of genomes [6]. In Arabidopsis thaliana, two genes (HMG1 and HMG2) encode three HMGR isoforms (HMGR1S, 
HMGR1L and HMGR2) [5,7]. It has been suggested that different variants of plant HMGR are physically associated with other enzymes, forming metabolons for the synthesis of particular isoprenoid products, and that these metabolons would be located at particular sites of the endomembrane system [8]. The association of sterol biosynthetic enzymes at the ER membrane (one of the branches of the isoprenoid pathway) has been shown in yeast, mammals and plants [9-11], but no proof of the existence of metabolons involving HMGR has yet been provided.

HMGR is composed of an N-terminal membrane domain, with low or no sequence similarity among eukaryotic kingdoms, and a highly conserved catalytic domain [12-14]. In plant HMGR, the membrane domain has only two hydrophobic segments, whereas in yeast and animal HMGR eight membrane-spanning regions have been predicted $[12,15,16]$. The three Arabidopsis HMGR isoforms are primarily targeted to the ER by the two hydrophobic sequences of the membrane domain that interact specifically with the Signal Recognition Particle [12,17]. However, immunolocalization whole-mount studies in Arabidopsis cotyledon suggested that endogenous HMGR mostly localizes within spherical vesicular structures, which were therefore named HMGR vesicles [18,19]. It is not known how the integral membrane protein HMGR reaches the inside of vesicular structures, nor what relationships exist between these vesicles and the ER.

Despite diverging evolution, the membrane domain of HMGR from the three eukaryotic kingdoms has the common capacity to induce massive proliferation of ER membranes that subsequently constitute Organized Smooth Endoplasmic Reticulum (OSER) structures [19-21]. When examined by transmission electron microscopy (EM), OSER structures contain tightly associated ER membranes according to three different patterns: ordered arrays with hexagonal or cubic symmetry (crystalloid ER), concentric layers (whorled ER) or simply stacked (lamellae or perinuclear karmellae) [21-23]. A highly conserved N-terminal motif of plant HMGR is required for OSER biogenesis [19], but no equivalent sequence has been identified in yeast or animal HMGR nor has the morphogenic mechanism been described. In Arabidopsis, OSER structures induced by the membrane domain of HMGR1S fused to GFP (1S:GFP chimera) also accumulate high amounts of endogenous HMGR and, therefore, have been named ER-HMGR domains [19].

Highly proliferated ER with ordered repetitive patterns was first described in the 1960s, as naturally occurring in diverse cell types from animals and plants [24-30] and as readily developing upon exposure to drugs [31,32]. Since then, diverse forms of hypertrophied ER have been identified in many natural and induced systems and referred to with a variety of terms, such as cotte de mailles [33], paracrystalline arrays [34], elaborate rings of granular $E R$ [35], double membrane arrays [36], tubuloreticular structures [37], undulating membranes [38], membrane lattice [39], stacks of flattened smooth ER [40], interlaced smooth surfaced tubules [41], compact areas of smooth membranes [42], paracrystalline ER [43], crystalloid membranes [44], organized smooth endoplasmic reticulum [45] or cubic membranes [46]. An exhaustive review [47], with about 200 examples, reported that cubic membranes (OSER structures) are broadly distributed in the three eukaryotic kingdoms. These structures are found in numerous cell types under certain physiological conditions or appear in response to stress or disease [47]. However, in most of the aforementioned studies, images were obtained by transmission EM after chemical fixation [47]. Alternative preparation and observation techniques are necessary to further expand our knowledge on OSER ultrastructure.

In this work we first study in more depth the subcellular location of Arabidopsis HMGR and, particularly, the HMGR vesicles. We also characterize ER-HMGR domains in Arabidopsis and Nicotiana cells, focusing on their biogenesis, ultrastructure and dynamism. Our EM analyses uncover differences in OSER ultrastructure because of the fixation method. We find that the ER-HMGR domains are flexible live entities, fully integrated in ER architecture and dynamism. 


\section{Results}

\subsection{Subcellular Location of Arabidopsis HMGR in WT and 1S:GFP Transgenic Plants}

Immunolocalization whole-mount studies in Arabidopsis cotyledon indicated that endogenous HMGR mostly localized inside HMGR vesicles ranging from 0.2 to $0.6 \mu \mathrm{m}$ in diameter [18]. These studies were done with a crude rabbit polyclonal antibody raised against the catalytic domain of Arabidopsis HMGR1 (Ab-CD1), but it was later reported that this serum cross-reacts with E. coli proteins [48]. Before proceeding with a deeper localization analysis of HMGR, we wanted to confirm the whole-mount studies with an immunopurified fraction of the antibody (Ab-CD1-i) [48]. In this improved assay, we confirmed that Arabidopsis HMGR mostly localizes in vesicular structures of parenchymal cells, in close proximity with chloroplast (Figure 1a-c). Our observations suggest that the HMGR vesicles can measure up to $2 \mu \mathrm{m}$ in diameter, somewhat more than previously reported.

We subsequently performed immunochemical transmission EM studies of the HMGR vesicles, both in wild type (WT) and 1S:GFP-overexpressing Arabidopsis plants. We used the immunopurified serum Ab-CD1-i to detect endogenous HMGR, and a commercial antibody against GFP (Ab-5450) to detect the chimeric 1S:GFP. We found selective deposition of gold particles on the surface and the inside of the HMGR vesicles, denoting the presence of both endogenous HMGR and the 1S:GFP chimera (Figure $1 \mathrm{~d}-\mathrm{f}, 1)$. The HMGR vesicles were associated in small groups connected by ER strands (Figure 1e,f,l). This connecting ER was also immunolabeled with the antibodies against HMGR and 1S:GFP (Figure 1e,l). The ultrastructural analysis uncovered that the HMGR vesicles were delimited by an ER membrane (Figure 1e). In addition, they possessed internal ER membranes (Figure 1d,f). Both the outer and internal membranes were recognized by the Ab-CD1-i (Figure 1d,e,l) and Ab-5450 (Figure 1f,l) antibodies. These results provide a rational explanation for the whole-mount detection of HMGR protein within HMGR vesicles.

As previously reported, overexpression of 1S:GFP in transgenic Arabidopsis plants induces ER proliferation and OSER structure biogenesis [19]. Whole-mount and immunochemical transmission EM analyses demonstrate colocalization of the 1S:GFP chimera and high levels of endogenous HMGR in the OSER formations (Figure 1g,l). Because of the presence of HMGR protein, we name them ER-HMGR domains. They have a disordered and heterogeneous crystalloid pattern, but with a characteristic layer of large loops in their external face and more compressed structures in the inside (Figure 1h,i,l). Precise deposition of immunogold particles indicates an abundance of 1S:GFP chimera and endogenous HMGR in the ER strands of ER-HMGR domains, both in the distended external loops and the internal membrane aggregates. High levels of the 1S:GFP chimera and endogenous HMGR were also detected in the ER network (Figure 1j,1) and nuclear envelope (Figure $1 \mathrm{j}, \mathrm{m})$. Few immunogold particles were observed inside the nucleus (Figure 1j), whereas no immunolabelling was found in the Golgi apparatus (Figure 1j), mitochondria (Figure 1h) or chloroplast (Figure 1d,h,j). In the negative control, no labelling was obtained without Ab-CD1-i and Ab-5450 primary antibodies (Figure 1k). 

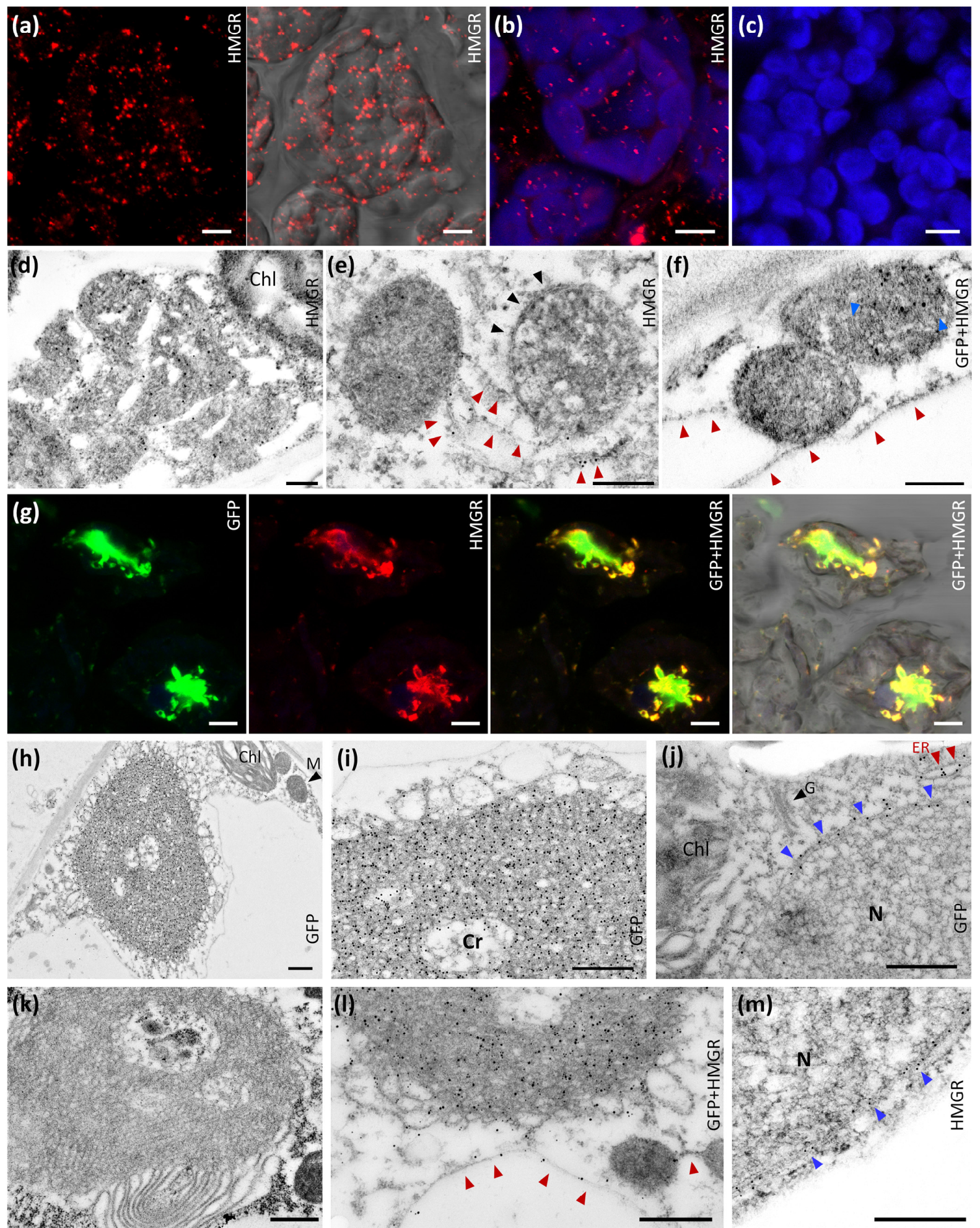

Figure 1. Arabidopsis HMGR localizes in the ER network, nuclear envelope, HMGR vesicles and ER-HMGR domains. (a-c) Whole-mount immunohistochemical analysis of cotyledon parenchymal cells from 6-day-old Arabidopsis WT seedlings (a) Immunodetection of HMGR with Ab-CD1-i and anti-rabbit IgG secondary antibody (Alexa Fluor 555, in red), visualized by confocal microscopy under dark (left) or bright fields (right). (b) Immunodetection of HMGR with Ab-CD1-i and antirabbit IgG secondary antibody (AlexaFluor 555, in red), and simultaneous detection of chlorophyll (in blue). (c) Negative control without the Ab-CD1-i antibody. The irregular corpuscles, 0.2 to $2 \mu \mathrm{m}$ in length, correspond to HMGR vesicles. The elliptic bodies, 6 to $8 \mu \mathrm{m}$ in diameter, correspond to chloroplasts. Images were obtained by Z-projection encompassing 3 (a), 10 (b) or 4 (c) $\mu \mathrm{m}$ in the Z-axis. Bars, $5 \mu \mathrm{m}$. (d-f) Immunochemical study of HMGR vesicles by transmission EM. Leaf samples from 10-day-old Arabidopsis WT or 1S:GFP seedlings were processed by HPF and embedded with Lowicryl 
HM20. (d) HMGR was detected in cotyledon from WT seedlings with Ab-CD1-i and anti-rabbit-IgG (18 nm particle). (e) HMGR was detected in true leaf from 1S:GFP seedlings with Ab-CD1-i and anti-rabbit-IgG (12 nm particle). (f) Double immunolocalization of HMGR and 1S:GFP in true leaf from 1S:GFP seedlings. HMGR was detected with Ab-CD1-i and anti-rabbit-IgG (12 nm particle) and 1S:GFP was detected with Ab-5450 and anti-goat-IgG (18 nm particle). Black and blue arrowheads indicate, respectively, the external and internal membranes from HMGR vesicles. Red arrowheads indicate ER strands. Bars, $250 \mathrm{~nm}$. (g) Whole-mount immunohistochemical analysis of cotyledon parenchymal cells from 6-day-old Arabidopsis 1S:GFP transgenic seedlings. 1S:GFP was detected with Ab-5450 and secondary antibody Alexa fluor 488 (green). HMGR was detected with Ab-CD1-i and secondary antibody Alexa fluor 594 (red). Images were obtained by Z-projection encompassing $12 \mu \mathrm{m}$ in the Z-axis. Bar, $5 \mu \mathrm{m}$. (h-m) Immunolocalization of HMGR and 1S:GFP by transmission EM. True leaves from 10-day-old Arabidopsis WT seedlings were processed by HPF and embedded with Lowicryl HM20. (h-j) 1S:GFP was detected with Ab-5450 and anti-goat-IgG (18 nm particle). (k) Negative control without Ab-CD1-i and Ab-5450. (1) Double immunolocalization of 1S:GFP (18 nm particle) and HMGR (12 nm particle). (m) HMGR was detected with Ab-CD1-i and anti-rabbit-IgG (12 nm particle). Chloroplast (Chl). ER strands (red arrowheads). Golgi apparatus (G). Mitochondria (M). Nuclear envelope (blue arrowheads). Nucleus (N). Bars, $500 \mathrm{~nm}$.

\subsection{Reversible Formation of ER-HMGR Domains}

To further characterize the biogenesis of ER-HMGR domains, we induced the transient expression of 1S:GFP in Nicotiana benthamiana leaves. The agroinfiltration approach allowed generalized and abundant expression of the 1S:GFP construct in leaf epidermis (Figure 2a). At day two after transfection, massive ER proliferation led to formation of OSER structures in the transfected tissue that were detectable even at low magnification (Figure 2a). Many small OSER structures appeared at ER network junctions and a single large OSER was formed around the nuclear envelope (Figure 2c,d). The 1S:GFPm construct, containing monomeric GFP, similarly induced small OSER structures at the network junctions and a large OSER aggregate around the nucleus (Figure 2b). As previously reported [19], this indicates that the membrane domain of Arabidopsis HMGR, and not its dimerizing GFP partner, induces ER proliferation and membrane association into OSER. In contrast to 1S:GFP, the 1S:GFPm chimera also accumulated in hypertrophied ER strands. Thick ER strands are usually present in epidermal cells and can be visualized with the ER-GFP luminal marker (Figure 2e), but become more prominent in the case of 1S:GFPm (Figure 2b). At day six after transfection, the expression of 1S:GFP was severely reduced. Concomitant with that, OSER structures virtually disappeared, with only some remnants around the nucleus and in the cytosol (Figure 2f). The resulting ER had the usual thick strands, although broad cisternae replaced the fine network (Figure 2f). ER cisternae are common in epidermal cells transfected with the luminal ER-GFP marker, although they have a smaller size (Figure 2e). Our observations in Nicotiana epidermal cells indicate that OSER biogenesis is reversible. The OSER structures are not a permanent consequence of transfection with 1S:GFP or 1S:GFPm, but can be replaced by quite normal ER when the levels of the chimeric protein decrease. 

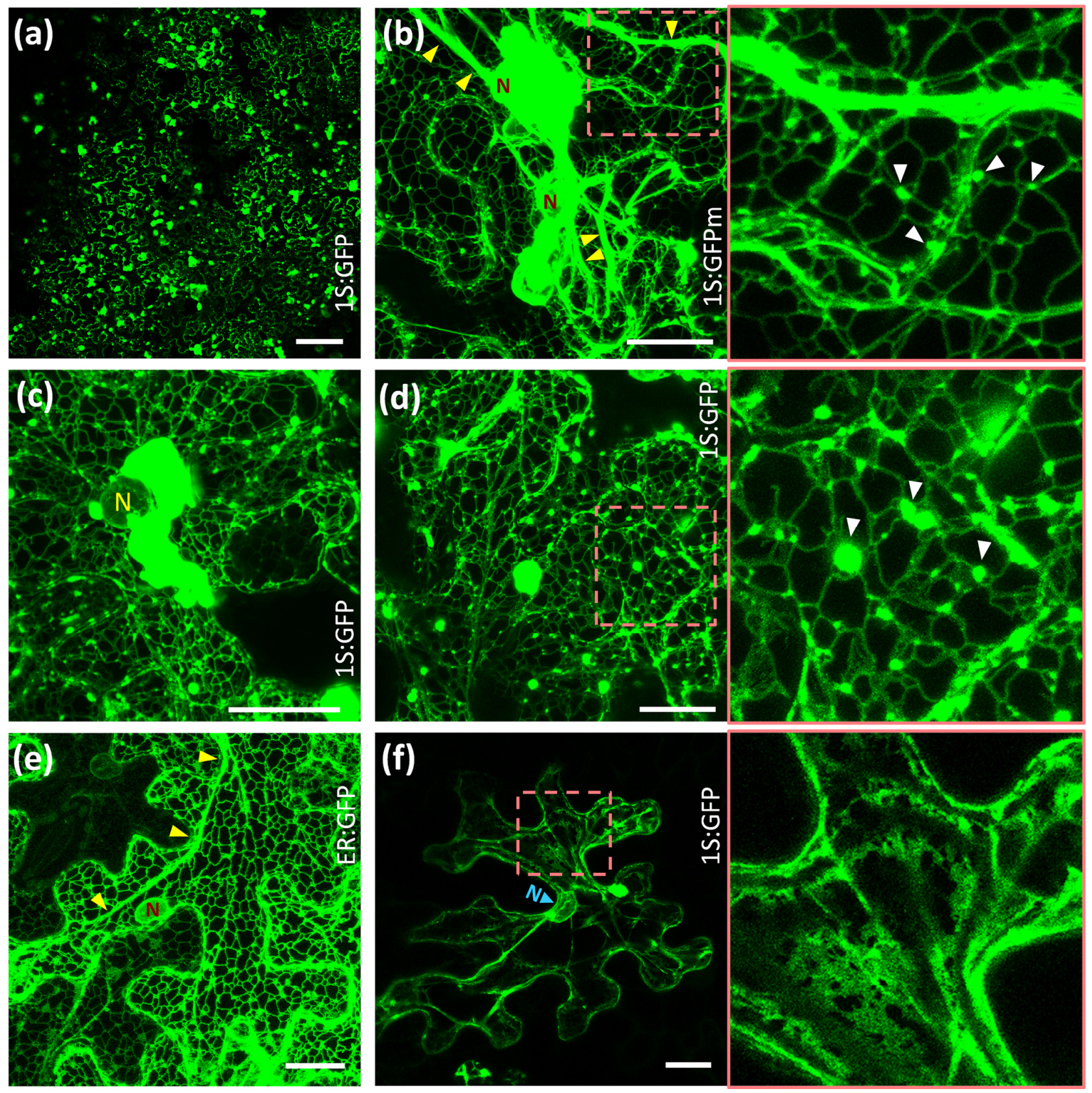

Figure 2. Reversible biogenesis of ER-HMGR domains in transfected Nicotiana cells. Nicotiana leaves were transfected with constructs encoding 1S:GFP (a,c,d,f), 1S:GFPm (b) or the control ER lumen marker ER:GFP (e) and epidermal cells were visualized by confocal laser microscopy. The expression time was 2 days (a), 3 days (b-e) or 6 days (f). The square regions indicated in $(\mathbf{b}, \mathbf{d}, \mathbf{f})$ are shown enlarged on the right. Images are a single section (a) or Z-projections encompassing 10 (b), 21 (c), 7 (d), 12 (e) or 14 (f) $\mu \mathrm{m}$ in the Z-axis. Nucleus (N). OSER structures (white arrowheads). Thick ER strands (yellow arrowheads). Bars, $100 \mu \mathrm{m}(\mathbf{a}), 20 \mu \mathrm{m}(\mathbf{b}-\mathbf{f})$.

\subsection{ER-HMGR Domains Are Highly Dynamic}

To further inspect OSER structure morphology and dynamism, we obtained transgenic Arabidopsis plants stably expressing the 1S:GFP construct. A panoramic view of seedling root epidermis showed high expression of the 1S:GFP chimera accumulating at the ER (Figure 3a). The transgenic construct induced large OSER structures (up to $10 \mu \mathrm{m}$ in diameter) around the nuclei and smaller OSER formations at ER network junctions (Figure 3a and Supplementary Movie 1). As previously reported [49,50], the ER network is highly dynamic with continuous strand movement and fusion or fission events. We found that 
OSER structures are connected to the ER network and participate in its dynamism. Many strands of the ER network associate with OSER formations (Figure 3b). The ER strands rapidly connect to, slide along or separate from the OSER surface (Supplementary Movie 2). Small OSER structures migrate along fine or thick ER strands, whereas the large OSER formations have a more limited motion (Supplementary Movies 1 and 2). In the nuclear OSER, this movement may imply a brief separation from the nuclear envelope (Supplementary Movie 1). OSER structures have spherical-ovoid shapes with slight continuous variation (Supplementary Movies 2 and 3). The OSER borders are not sharp, but have a fluctuating blurry aspect (Figure 3b,c), suggesting the incorporation or emergence of GFP-labelled material (likely membranes) in the OSER surface (Supplementary Movies 2 and 3). We conclude that, in Arabidopsis cells, OSER structures are highly dynamic entities. They change in shape, have a moving surface and migrate intracellularly.
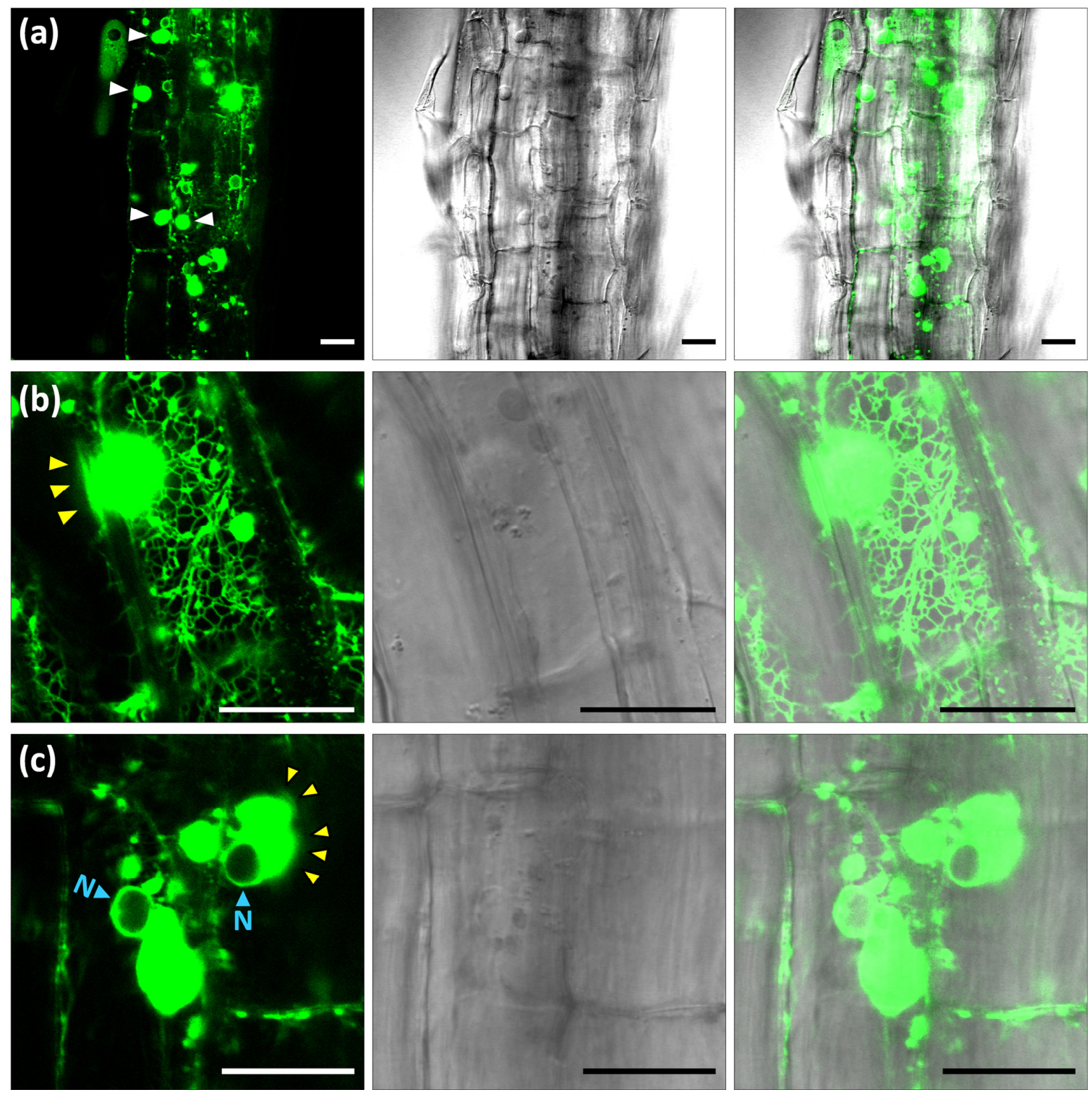

Figure 3. Characterization of ER-HMGR domains in Arabidopsis 1S:GFP transgenic plants. Arabidopsis 1S:GFP 9-day-old seedlings were analysed by confocal laser microscopy. The pictures show three channels (GFP, bright field and merge) of single sections from root epidermal cells that were subsequently characterized by live imaging: (a) panoramic view of root epidermis with large ER-HMGR domains indicated by white arrowheads (Supplementary Movie 1); (b) large ER-HMGR domain with dynamic connections to the ER network (Supplementary Movie 2); (c) nuclear ER-HMGR domains with changing spherical-ovoid shape (Supplementary Movie 3). Blurry fluctuating borders (yellow arrowheads). Nucleus (N). OSER structures (white arrowheads). Bars, $20 \mu \mathrm{m}$. 


\subsection{The Fixation and Dehydration Method Severely Affects OSER Ultrastructure}

Our above confocal microscope observations of ER-HMGR domains do not fit the concept of OSER structures as rigid entities. Their tight, repetitive pattern, obtained after chemical fixation, contrasts with the flexibility and dynamism of OSER structures. To capture single states of OSER change at the ultrastructure level, we expressed 1S:GFP in Nicotiana leaf and submitted samples to high-pressure freezing (HPF) followed by freezesubstitution, to finally observe epidermal cells by transmission EM. We compared the HPF results with those of chemical fixation and subsequent dehydration at room temperature. With either method, OSER structures show a combination of crystalloid, lamellar and whorled membrane patterns (Figure $4 a, b, g, h, j$ ). In both cases, there is also a coincidence in cytosolic and luminal spaces. Luminal spaces correspond to the continuous internal cavity of the ER and have an electron-lucent aspect at transmission EM (Figure $4 \mathrm{~b}, \mathrm{f}, \mathrm{i}, \mathrm{k}$ ). Cytosolic spaces result from the apposition of adjacent ER membranes and have a quite constant width, which is about $10-15 \mathrm{~nm}$ in both chemical and HPF fixation (Figure $4 \mathrm{~b}, \mathrm{f}, \mathrm{i}, \mathrm{k}$ ). Cytosolic spaces have a darker aspect than luminal spaces, probably reflecting the presence of proteins that mediate the intermembrane attachment.

In spite of the above-mentioned coincidences, OSER structures have quite different overall morphology depending on the fixation method. The most remarkable feature of OSER formations after chemical fixation is the presence of highly repetitive convoluted membranes, which have a very different smooth and turgid aspect in HPF images (Figure $4 \mathrm{a}, \mathrm{c}, \mathrm{e}, \mathrm{h}, \mathrm{i})$. The convoluted pattern is exclusive to chemically fixed crystalloid domains, whereas aligned membranes are present in whorled domains, both with HPF and chemical fixation (Figure $4 b, j, k$ ). However, the crystalloid (Figure $4 a, c, d$ ) and whorled (Figure $4 \mathrm{~b}$ ) domains are far looser after HPF than after chemical fixation (Figure $4 \mathrm{~h}, \mathrm{j}$ ). The morphological heterogeneity generated by fixation is not due to the cytosolic spaces, which are always narrow and uniform, but occurs in the luminal spaces (Figure $4 \mathrm{~b}, \mathrm{f}, \mathrm{i}, \mathrm{k}, \mathrm{k}$ ). The small size and regularity of luminal spaces obtained after chemical fixation contributes to the repetitive pattern (Figure $4 \mathrm{~h}, \mathrm{i}$ ). In contrast, HPF results in larger turgid luminal spaces, which are very variable in size and morphology (Figure 4e,f). After HPF and subsequent embedding by two alternative methods, the OSER morphology is disordered and heterogeneous, but has the above-mentioned row of large loops at the periphery and is internally more compact (see similarities of Figure $4 \mathrm{a}, \mathrm{c}, \mathrm{d}$ with Figure $1 \mathrm{~h}, \mathrm{i}, \mathrm{l}$ ).

To confirm the OSER ultrastructure resulting from chemical fixation, we expressed the membrane domain of Arabidopsis HMGR1S fused to monomeric GFP (chimera 1S:GFPm) in Nicotiana cells. Constructs 1S:GFP and 1S:GFPm differ in just one amino acid residue [19]. The 1S:GFPm chimera generated crystalloid, lamellar and whorled patterns with constant cytosolic distance between membranes and also regular luminal spaces (Figure 41-0), similar to those obtained with 1S:GFP (Figure $4 \mathrm{~h}-\mathrm{j}$ ). However, in OSER structures derived from 1S:GFPm the core of crystalloid domains was usually looser than the peripheral parts (Figure 4m). This was not observed in OSER structures derived from 1S:GFP, even when they were much larger (Figure 5e). We conclude that the dimerizing capacity of GFP may influence OSER membrane compaction during the chemical fixation process. 

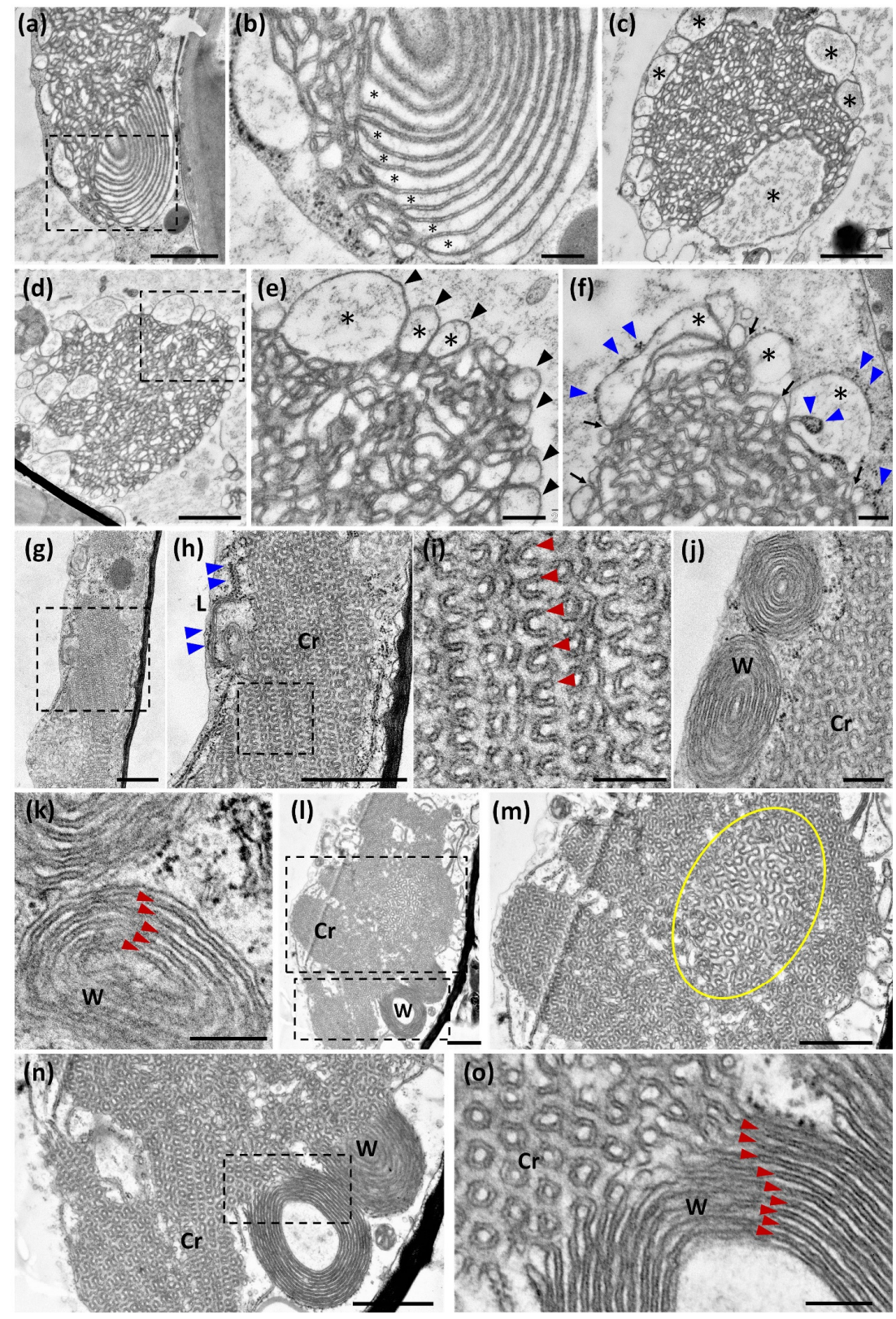

Figure 4. Ultrastructural analysis of ER-HMGR domains in Nicotiana epidermal cells. Three days after agroinfiltration with 1S:GFP (a-k) or 1S:GFPm (1-o), Nicotiana leaves were processed for transmission EM. (a-f) 1S:GFP-transfected leaves were submitted to HPF and embedded in Epon resin. (a) Panoramic view ER-HMGR domain with a crystalloid region in sagittal section and a whorled region in transversal section. (b) Magnified region of panel (a), to show the clear luminal spaces alternating with darker (denser for electrons) cytosolic spaces. (c,d) Panoramic view of crystalloid ER-HMGR domains with large loops surrounding the internal, more compact structure. (e) Magnified region of (d) with large loops. (f) Crystalloid structure with interspersed clear-luminal and dark-cytosolic spaces. The OSER cytosolic spaces are continuous with the cytoplasm (black arrows). Ribosomes are visible at the external face of the OSER structure. Occasionally, they are trapped in internal cytosolic spaces, near the periphery of the ER aggregate. (g-k) 1S:GFP-transfected leaves were submitted to chemical fixation and embedded in Spurr resin. (g) Panoramic view of crystalloid ER-HMGR domain. (h) Magnified region of (g) to show the repetitive smooth ER and a thin lamellar region on the left side. Ribosomes are excluded from the ER-HMGR domain. (i) Magnified regions of (h). (j) Whorled and crystalloid regions. (k) Whorled region with regular cytosolic and luminal spaces. (1-o) 1S:GFPm-transfected leaves were submitted to chemical fixation and embedded in Spurr resin. (1) Panoramic view of ER-HMGR domain with crystalloid, lamellar and whorled patterns. (m) Magnified region of (1) to show the looser region (circled) in the core of the ER-domain. (n) Magnified region of (1) to show the transition between whorled and crystalloid regions. (o) Magnified region of (n). Large membrane loops (black arrowheads). Crystalloid region (Cr). Cytosolic spaces (red arrowheads). Lamellar region (L). Luminal spaces (asterisks). Ribosomes (blue arrowheads). Whorled region (W). Bars, $1 \mu \mathrm{m}(\mathbf{a}, \mathbf{c}, \mathbf{d}, \mathbf{g}, \mathbf{h}, \mathbf{l}-\mathbf{n}), 200 \mathrm{~nm}(\mathbf{b}, \mathbf{e}, \mathbf{f}, \mathbf{i}-\mathbf{k}, \mathbf{o})$. 


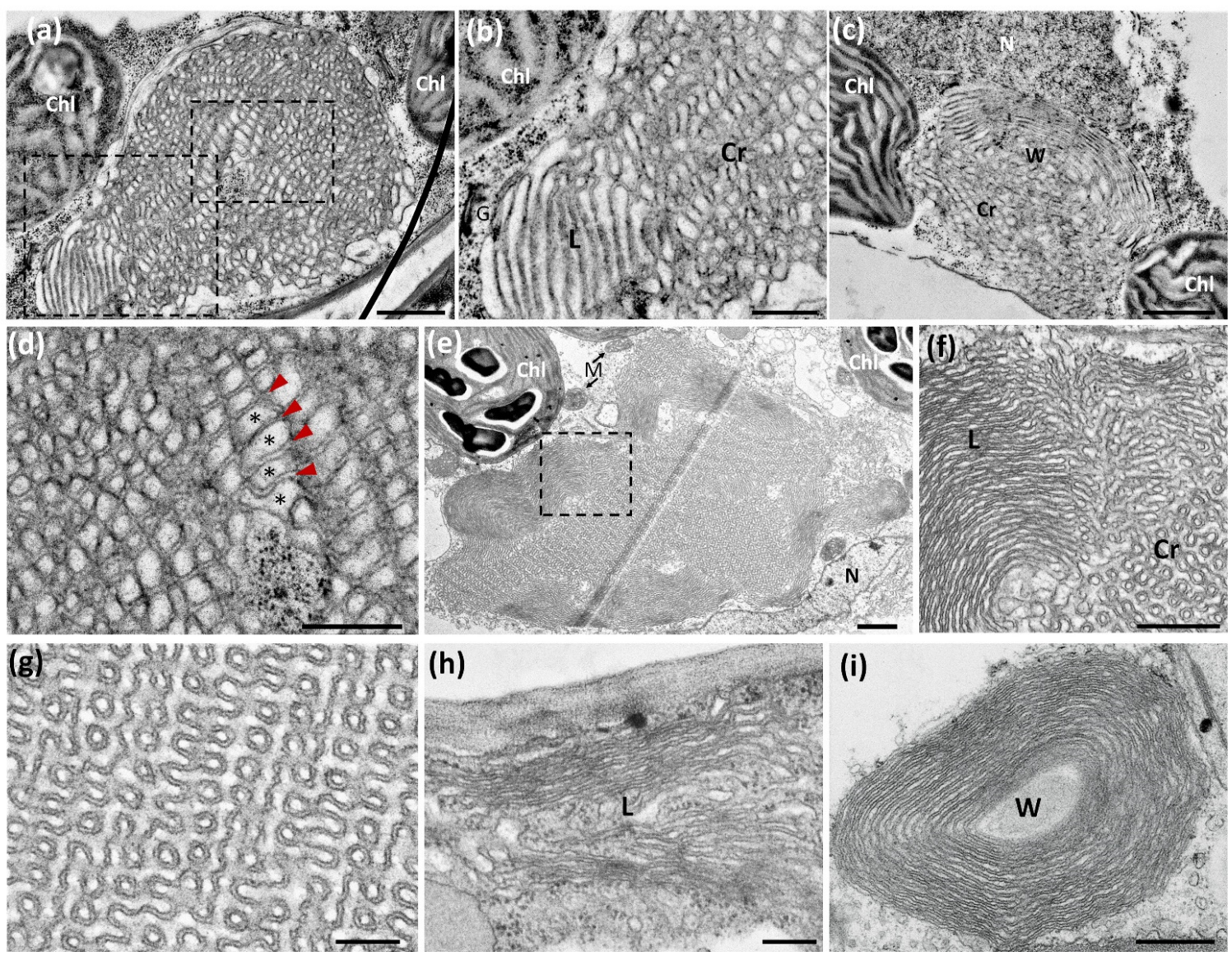

Figure 5. Ultrastructural analysis of ER-HMGR domains in Arabidopsis parenchymal cells. Emerging true leaves from Arabidopsis 10-day-old seedlings transgenic for 1S:GFP were submitted to HPF or chemical fixation and embedded in Spurr resin. (a-d) Samples obtained by HPF. (a) Panoramic view of a crystalloid-lamellar ER-HMGR domain located between chloroplasts. (b) Magnified region of panel (a), to show the transition between crystalloid and lamellar regions. (c) Nuclear ER-HMGR domain with crystalloid and whorled patterns. (d) Magnified region of (a), to show alternation of cytosolic (dark) and luminal (clear) spaces. Notice the narrow homogenous width of the cytosolic spaces and the broader and more variable size of the luminal spaces. (e-i) Samples obtained by chemical fixation. (e) Panoramic view of ER-HMGR domain with crystalloid, lamellar and whorled patterns. Notice the large size of the OSER structure (12 $\mu \mathrm{m}$ long). (f) Magnified region of panel (e), to show the transition between lamellar and crystalloid regions. (g) Detail of a crystalloid structure to show the repetitive pattern of dark cytosolic spaces and lighter luminal spaces. (h) Lamellar ER-HMGR domain. (i) Whorled ER-HMGR domain. Chloroplast (Chl). Crystalloid region (Cr). Cytosolic spaces (red arrowheads). Golgi apparatus (G). Lamellar region (L). Luminal spaces (asterisks). Mitochondria (M). Nucleus (N). Whorled region (W). Bars, $1 \mu \mathrm{m}(\mathbf{a}, \mathbf{c}, \mathbf{e})$, $500 \mathrm{~nm}(\mathbf{b}, \mathbf{d}, \mathbf{f}, \mathbf{i}), 200 \mathrm{~nm}(\mathbf{g}, \mathbf{h})$.

We also examined OSER ultrastructure in the emerging true leaves of the 1S:GFP Arabidopsis seedlings (10-day-old transgenic plants). We observed OSER structures with crystalloid, lamellar and whorled membrane patterns in parenchymal cells of both HPF and chemically fixed samples (Figure 5a,c,f). As mentioned above for Nicotiana, in Arabidopsis cells the three OSER ultrastructural patterns had a more relaxed morphology after HPF than after chemical fixation (Figure $5 \mathrm{a}, \mathrm{b}, \mathrm{e}, \mathrm{f}$ ). This is due to larger and more variable luminal spaces in HPF than in chemical fixation samples, whereas the dark cytosolic spaces had a similar width in both techniques (Figure $5 b, d, g-i)$. The convoluted patterns observed in crystalloid domains after chemical fixation were absent in samples obtained by HPF (Figure $5 d, g$ ). Since HPF and chemical fixation were performed in parallel from the same samples, we conclude that the morphological differences of 1S:GFP-containing OSER were 
generated during the fixation process. Equivalent results were obtained in the two assayed systems, transfected Nicotiana leaves and Arabidopsis seedlings. As HPF immobilizes water and prevents its loss from the sample, the resulting transmission EM images are likely more similar to native OSER than those obtained by chemical fixation. In addition, the results obtained by HPF are more consistent with a dynamic view of the ER-HMGR domains observed with the confocal microscope.

\section{Discussion}

We found that Arabidopsis HMGR has several subcellular locations, such as the ER network, the nuclear envelope, HMGR vesicles, and the hypertrophied ER-HMGR domains. However, all these compartments are morphological variations of the ER. Therefore, our immunochemical results uncover that the primary targeting site of Arabidopsis HMGR is also its final subcellular destination. This protein does not migrate through the endomembrane system. Our observations underline the importance of the membrane domain of HMGR, which not only determines its primary and final destination sites, but also induces ER proliferation and OSER biogenesis. The resulting OSER structures (ER-HMGR domains) accumulate high levels of the chimeric 1S:GFP and endogenous HMGR ([19] and this work). Our transient expression assays indicate that the ER-HMGR domains disappear when the expression of 1S:GFP decreases, thus re-establishing normal ER morphology. A similar observation was made in transgenic Arabidopsis plants in which 1S:GFP expression suffered silencing after a few weeks of development [19]. Hence, in non-transfected cells natural OSER could also form or disappear, depending on the expression level of endogenous OSER-inducing proteins.

The HMGR vesicles have an outer membrane enclosing membrane material and the whole structure remains connected to the ER network. Both the internal and surrounding membranes are recognized by antibodies against HMGR and 1S:GFP, which denote ER identity. We therefore conclude that the HMGR vesicles are membrane aggregates that derive directly from the ER. The HMGR localized in the outer and the internal membranes might be metabolically active. Thus, HMGR vesicles could be a differentiated organelle of the ER involved in the synthesis of particular isoprenoid products. Additional experiments, such as metabolic labelling assays or the localization of other enzymes of the isoprenoid pathway, are required to determine whether the HMGR vesicles contain functional metabolon-like assemblies.

The HMGR domains are not a mere consequence of the accumulation of proliferated membranes in the cytosol, but behave as live structures. The OSER aggregates are an integral part of the ER network and participate in its dynamism. Small ER-HMGR domains migrate along ER strands, whereas the large ones have a more limited motion. The large OSER formations reversibly establish dynamic connections to the ER network. The ERHMGR domains show a slow but steady change in shape, alternating between ovoid and spherical forms. Particularly intriguing are the fluctuating borders of ER-domains, which suggest continuous incorporation or release of 1S:GFP-containing material. This interpretation is reinforced by ultrastructural and immunolabelling EM studies, showing that the ER-HMGR domains have a layer of large membrane loops with 1S:GFP that surround the more compressed core. Such a morphology suggests that the OSER periphery is a site for membrane compaction or unfolding. Since samples were prepared from growing Arabidopsis and Nicotiana leaves engaged in high expression of 1S:GFP and ongoing OSER biogenesis, the moving and static images likely indicate incorporation of new membranes to the OSER aggregate. Therefore, our results suggest that crystalloid OSER structures incorporate ER membranes in their external face with subsequent compression (reduction of luminal spaces) to the inside.

Our finding that OSER structures are loose, dynamic and flexible entities could explain previous observations. The OSER-inducing chimera cytochrome b(5)-GFP was highly mobile within OSER structures and diffused rapidly between these formations and the ER network [45]. The stacked membrane associations (karmellae) produced by HMGR 
overexpression in yeast did not interfere with protein transit from the ER to the Golgi apparatus [51]. Overexpression of rat liver aldehyde dehydrogenase in monkey COS-1 cells induced OSER formations, but the resulting crystalloid ER did not disturb protein transport from the ER to plasma membrane or lysosomes [44]. In hamster UT-1 cells, the G protein from vesicular stomatitis virus entered and egressed from OSER aggregates freely, without apparent restriction [52]. This fast transit of proteins across OSER formations seems difficult to reconcile with the small luminal spaces and apparently rigid architecture deduced at EM after chemical fixation. The above observations are more consistent with the broad luminal spaces of OSER structures obtained by HPF and the high flexibility and dynamism seen by live imaging with the confocal microscope.

We have analysed OSER ultrastructure by transmission EM after either chemical fixation or HPF. In both cases, OSER formations are similarly composed of crystalloid, lamellar and whorled patterns, indicating that this structural diversity is not generated during fixation, but is present in the original aggregates. The two fixation methods are also reproducible in the narrow cytosolic spaces between OSER membranes. The cytosolic spaces are dense for electrons in both methods and have a constant width. These two features may suggest that membrane apposition at a fixed distance is mediated by specific proteins. In morphological free-fracture EM analysis of animal crystalloid OSER structures, a high density of homogenous particles were protruding from the cytosolic side of the internal membranes [53]. These particles may correspond to intermembrane protein bridges, the components of which should be highly abundant in the crystalloid domain.

Cryoimmobilization is regarded as the most reliable fixation strategy for ultrastructural analysis by transmission EM [54]. Diverse artefacts, particularly affecting cellular membranes, are produced by chemical fixation. It was believed that gram-positive bacteria possessed mesosomes in their plasma membrane, but it was later found that such folded invaginations are not natural but produced by chemical fixation [55-57]. Similarly, in sea-urchin eggs, glutardehyde fixation caused the formation of large membrane vesicles at the initial site of fusion between plasma and granule membranes [58]. More recently, in a human cell-line transformed with Epstein-Barr virus, aldehyde fixation notably reduced endosomal volume, without affecting the length of its outer membrane [59]. Thus, chemically fixed early endosomes became irregular ovoid bodies with broad protruding tubules, whereas after cryofixation the same organelles were round and turgid with an incidental short tubule [59]. It was proposed that this endosome shrinkage was produced by dehydration during chemical fixation [59]. Chemical fixation could similarly dehydrate the luminal spaces of OSER structures, without affecting membrane length. This would produce an overall shrinkage in the OSER formation, concomitant with membrane accommodation in convoluted shapes. We reproducibly obtained the convoluted membranes after chemical fixation, but never after HPF, although both methods were applied to equivalent Arabidopsis or Nicotiana samples. It is somehow amazing that a crystal-like pattern can develop from disordered and turgid membranes by the mere application of chemical fixative agents. However, it would be even more surprising that OSER morphologies having smooth turgid membranes, heterogeneous luminal spaces and large peripheral loops were generated in HPF treatment from a hypothetical native convoluted pattern. We therefore propose that the OSER ultrastructure observed after HPF is closest to the original morphology existing in vivo.

OSER structure depictions have been obtained by transmission EM from a large variety of chemically fixed eukaryotic cells and tissues, always with similar convoluted shapes in crystalloid domains [47]. Therefore, we believe that a common feature of OSER membranes may guide their compaction during chemical fixation. The aggregated lipid bilayers are highly enriched in the OSER-inducing protein and few other uncharacterized polypeptides [60,61]. For instance, not only 1S:GFP but also endogenous HMGR accumulate at high levels in ER-HMGR domains ([19] and this work). Any of these proteins could selfassociate, GFP as a dimer or HMGR as a tetramer [62,63]. Highly abundant self-associating 
proteins could then provide a structural frame to build the crystal-like convoluted pattern that would be established during slow dehydration and chemical cross-linking.

Crystalloid ultrastructural patterns generated by 1S:GFP were homogeneous and compact, whereas those generated by 1S:GFPm had a looser core (Figure $4 \mathrm{~g}, \mathrm{~h}, \mathrm{~m}$ ), indicating that the presence of monomeric GFP instead of the original dimerizing GFP was responsible for the difference. Since chemical fixatives rely on diffusion to penetrate the sample and are consumed during fixation, their effects are discontinuous with slower cross-linking in the inside [54]. We speculate that this temporal discontinuity, together with a lower association capacity of 1S:GFPm with respect to 1S:GFP, could reduce membrane compaction at the core of the crystalloid domain. Independently of the molecular mechanism, the heterogeneous membrane compaction with 1S:GFPm reinforces the notion that chemical fixation may illegitimately affect OSER ultrastructure.

\section{Materials and Methods}

\subsection{Plant Material}

Experiments were performed with Arabidopsis (Arabidopsis thaliana) WT Col 0 or a transgenic line overexpressing 1S:GFP in the same genetic background. The preparation of the 1S:GFP transgenic line was described previously [19]. In this line, 1S:GFP is under control of the cauliflower mosaic virus $35 \mathrm{~S}$ promoter, which confers high expression in the whole plant. Seeds were surface sterilized by washing three times with $70 \%(v / v)$ ethanol and three times with $100 \%(v / v)$ ethanol, sowed in petri dishes with half concentrated Murashige and Skoog (MS) medium [64] and vernalized at $4{ }^{\circ} \mathrm{C}$ for $3 \mathrm{~d}$. Growth was at $22-24{ }^{\circ} \mathrm{C}$ and long day conditions ( $16 \mathrm{~h}$ light/ $8 \mathrm{~h}$ darkness).

\subsection{Constructs}

The identity and source of protein constructs was as follows: 1S:GFP and 1SGFPm, N-terminal fragment 1-178 from Arabidopsis HMGR1S (accession AAF16652) fused, respectively, to GFP or monomeric GFP [19]. ER:GFP, GFP sequence with appended ER signal peptide at the $\mathrm{N}$-terminus and ER retention signal at the $\mathrm{C}$-terminus, encoded by plasmid pVKH-GFP-HDEL [65].

\subsection{Transient Expression in Nicotiana Benthamiana Leaves}

Transient expression of 1S:GFP and 1S:GFPm in N. benthamiana leaves was achieved by agroinfiltration as previously described [66]. 1S:GFP and 1S:GFPm was previously cloned into plasmid pPCV002 under control of the cauliflower mosaic virus $35 \mathrm{~S}$ promoter, which confers high constitutive expression [19]. The pPCV002 derivatives were transformed into Agrobacterium tumefaciens strain GV3101 pMP90RK [67]. The transformed bacteria were grown in YEB medium (per litre: $5 \mathrm{~g}$ beef extract, $1 \mathrm{~g}$ yeast extract, $5 \mathrm{~g}$ bacteriological peptone, $5 \mathrm{~g}$ sucrose, $2 \mathrm{mmol} \mathrm{MgSO}_{4}$ ) containing $100 \mu \mathrm{g} / \mathrm{mL}$ each of kanamycin, rifampicin and carbenicillin at an $\mathrm{OD}_{600}$ of 0.5 to 1.0. Cells were harvested by centrifugation and suspended in $10 \mathrm{mM} \mathrm{N}$-morpholino ethanesulfonic acid (MES, pH 5.7), $10 \mathrm{mM} \mathrm{MgCl}$ and $0.2 \mathrm{mM}$ acetosyringone to an $\mathrm{OD}_{600}$ of 1.0. Bacteria were infiltrated into leaves with a 1-mL disposable syringe without a needle. Expression was examined daily, until day 6 after agroinfiltration.

\subsection{Source and Use of Antibodies}

The catalytic domain of Arabidopsis HMGR1S (CD1) produced in Escherichia coli was used as immunogen to produce a polyclonal antibody in rabbit and the resulting serum was immunosubstracted to remove IgG reacting against the bacterial proteins [48]. The immunopurified serum (Ab-CD1-i) was used as primary antibody at 1:500 for whole mount and 1:1000 for transmission EM. Anti-rabbit IgG secondary antibodies for HMGR detection were code Ab150066 (Abcam, Toronto, ON, Canada) coupled to Alexa Fluor-555 at 1:1000 for whole mount (Figure 1a,b), code Ab150068 (Abcam, Toronto, ON, Canada) coupled to Alexa Fluor-594 at 1:1000 for whole mount (Figure 1g), code 111-215-144 (Jackson Im- 
munoresearch, Cambridge, UK) coupled to an 18-nm gold particle at 1:30 for transmission EM (Figure 1d) and code 111-205-144 (Jackson Immunoresearch, Cambridge, UK) coupled to a 12-nm gold particle at 1:30 for transmission EM (Figure 1e,f,l,m).

GFP was detected with Ab-5450 (Abcam, Toronto, ON, Canada) as the primary antibody at 1:1000 for whole mount and transmission EM. Anti-goat IgG secondary antibodies for GFP detection were code Ab150133 (Abcam, Toronto, ON, Canada) coupled to Alexa Fluor-488 at 1:1000 for whole mount, and code 705-215-147 (Jackson Immunoresearch, Cambridge, UK) coupled with an 18-nm gold particle at 1:15 for transmission EM.

\subsection{Immunolocalization in Whole Mount}

Whole-mount in situ immunolocalization was done as described [68] with modifications. After fixation in $4 \%(w / v)$ paraformaldehyde, seedlings were incubated in methanol to remove chlorophylls. Five cycles of seedling freezing and thawing on glass slides were performed to permeate tissue, followed by incubation with 2\% (w/v) Driselase (D8037; Sigma Aldrich-Merk, Madrid, Spain) to allow for the penetration of antibodies through the plant cell wall. After blocking with $3 \%(w / v)$ bovine serum albumin (BSA) solution, simultaneous incubation with one or two primary antibodies (Ab-CD1-i at 1:500, Ab-5450 at 1:1000) was performed directly on the slides. Samples were then washed with phosphatebuffered saline (PBS) and incubated with the corresponding secondary antibody at 1:1000. The secondary antibody to detect HMGR was Abcam Ab150066 (Alexa Fluor-555) or Ab150068 (Alexa Fluor-594). The secondary antibody to detect GFP was Abcam Ab150133 (Alexa Fluor-488). After washing with PBS, samples were sealed for observation at the confocal microscope.

\subsection{Confocal Microscopy}

Confocal laser microscopy was performed with spectral microscope Olympus FV1000 (objectives UPLSAPO 60x O, numerical aperture: 1.35 and UPLSAPO 60x W, numerical aperture: 1.20) or Leica TCS SP5 (objectives HCX PL APO CS 40x/1.25 Oil UV, HCX PL APO $63 x / 1.20 \mathrm{~W}$ corrected for UV, and HCX PL APO CS 63x/1.20 water UV) at room temperature. Fluorophores were detected with the following excitation and emission wavelengths: GFP $($ excitation $=488 \mathrm{~nm}$, emission $=500-545 \mathrm{~nm})$, Alexa Fluor $-555($ excitation $=559 \mathrm{~nm}$, emission $=570-610 \mathrm{~nm})$ and Alexa Fluor-594 $($ excitation $=559 \mathrm{~nm}$, emission $=575-620 \mathrm{~nm})$ and chlorophyll (excitation $=559 \mathrm{~nm}$, emission $=640-680 \mathrm{~nm}$ ). Images were acquired with the software FV10-ASW 4.1 (Olympus, Hamburg, Germany) and LAS AF 2.7.3.9723 (Leica Microsystems, Wetzlar, Germany) and processed with the software ImageJ 1.50i (http:/ /imagej.nih.gov/ij, accessed on 28 May 2020).

\subsection{Chemical Fixation for Ultrastructural Studies}

Explants from Nicotiana leaves or Arabidopsis seedlings were excised under a stereomicroscope and transferred to glass vials filled with $1.5 \%(v / v)$ paraformaldehyde and $1.5 \%$ $(v / v)$ glutaraldehyde in $0.1 \mathrm{M}$ cacodylate buffer ( $\mathrm{pH} 7.4)$ containing $2 \mathrm{mM} \mathrm{CaCl}_{2}$. The vials were degassed briefly to allow penetration of the fixative into tissue and incubated at $4{ }^{\circ} \mathrm{C}$ for $24 \mathrm{~h}$. After washing with the cacodylate- $\mathrm{CaCl}_{2}$ buffer without fixative, samples were post-fixed for $3 \mathrm{~h}$ at $4{ }^{\circ} \mathrm{C}$ with $1 \%(w / v)$ osmium tetroxide and $0.8 \%(w / v) \mathrm{K}_{3} \mathrm{Fe}(\mathrm{CN})_{6}$ in the same buffer. Samples were subsequently dehydrated in acetone, infiltrated with Spurr resin for $2 \mathrm{~d}$, embedded in the same resin and polymerized at $60^{\circ} \mathrm{C}$ for $48 \mathrm{~h}$.

\subsection{High-Presure Freezing (HPF) for Ultrastructural Studies}

Explants from Nicotiana leaves or Arabidopsis seedlings were excised under a stereomicroscope and transferred to aluminium planchette with a $200 \mu \mathrm{m}$-deep cavity that was subsequently filled with yeast (Saccharomyces cerevisiae) paste and cryoimmobilized immediately with a high pressure freezer (EM Pact (Leica)). Freeze substitution of frozen samples was performed in an automatic freeze substitution system (EM AFS (Leica)) with acetone containing $2 \%(w / v)$ osmium tetroxide and $0.1 \%(w / v)$ uranyl acetate, for $3 \mathrm{~d}$ at 
$-90{ }^{\circ} \mathrm{C}$. On the fourth day, the temperature was raised by $5{ }^{\circ} \mathrm{C}$ per hour to room temperature. At this temperature, samples were rinsed in acetone, infiltrated with Epon (Nicotiana samples, Figure 4) or Spurr (Arabidopsis samples, Figure 5) resin for $2 \mathrm{~d}$, embedded in a thin layer of the same resin and polymerized at $60{ }^{\circ} \mathrm{C}$ for $48 \mathrm{~h}$.

\subsection{Ultrastructural Analysis}

Embedded blocks for ultrastructural analysis were submitted to thin sectioning and cell integrity was confirmed at the light microscope. Ultrathin sections were obtained using an Ultracut UC6 Ultramicrotome (Leica) and mounted on Formvar-coated copper grids. Samples were stained with $2 \%(w / v)$ uranyl acetate in water and lead citrate. Samples were observed in a JEM-1010 Electron Microscope (JEOL) equipped with a CCD Camera SIS Megaview III and the AnalySIS software. After capture, image brightness and contrast were adjusted with ImageJ $1.50 \mathrm{i}$ for a better visualization.

\subsection{Immunochemical Ultrastructural Analysis}

Explants from Arabidopsis seedlings were cryoimmobilized by high-pressure freezing using an EM Pact (Leica) with yeast paste as the filler. Freeze substitution of frozen samples was performed in an automatic freeze substitution system (EM AFS (Leica)) with methanol containing $0.5 \%(w / v)$ uranyl acetate at $-90^{\circ} \mathrm{C}$ for $3 \mathrm{~d}$. On the fourth day, the temperature was raised by $5{ }^{\circ} \mathrm{C}$ per hour to $-50{ }^{\circ} \mathrm{C}$. At this temperature, samples were rinsed in acetone, infiltrated and flat embedded in Lowicryl HM20 for $4 \mathrm{~d}$. Ultrathin sections were picked up on Formvar-coated nickel grids. Sample-containing grids were incubated on drops of PBS with 5\% (w/v) BSA for $20 \mathrm{~min}$ at room temperature. After removal of the washing solution, drops of PBS with the primary antibody (Ab-CD1-i or Ab-5450 at 1:1000) and $1 \%(w / v)$ BSA were added and incubated for $2 \mathrm{~h}$. Grids were washed three times for 30 min with a drop of PBS with $0.25 \%(v / v)$ Tween 20 and incubated for $1 \mathrm{~h}$ in drops of PBS with the secondary antibody and $1 \%(w / v)$ BSA. Secondary antibodies (at 1:30) for HMGR detection were codes 111-205-144 (12-nm gold particle) or 111-215-144 (18-nm particle) from Jackson Immunoresearch (Cambridge, UK). The secondary antibody for GFP detection (code 705-215-147; 18-nm particle; Jackson Immunoresearch, Cambridge, UK) was used at 1:15. The grids were washed three times with a drop of PBS for 5 min and two times with distilled water and air-dried. In control assays for the nonspecific binding of the gold-conjugated antibody, the primary antibody was omitted. Sections were stained with $2 \%(w / v)$ uranyl acetate in water and lead citrate and observed in a JEM-1010 electron microscope (JEOL) with an SIS Mega View III CCD camera.

Supplementary Materials: The following are available online at https:/ / www.mdpi.com/article/10 $.3390 /$ ijms22179132/s1.

Author Contributions: Conceptualization, N.C. and R.E.G.-T.; methodology, R.E.G.-T., C.L.-I. and N.C.; validation, R.E.G.-T. and N.C.; investigation, R.E.G.-T. and N.C.; resources, N.C.; data curation, N.C.; writing—original draft preparation, N.C.; writing—review and editing, N.C. and C.L.-I.; visualization, R.E.G.-T. and N.C.; supervision, J.C.F. and N.C.; project administration, N.C.; funding acquisition, J.C.F. and N.C. All authors have read and agreed to the published version of the manuscript.

Funding: This research was funded by the Generalitat de Catalunya (grant 2017SGR710), Centres de Recerca de Catalunya (CERCA), the Ministerio de Asuntos Exteriores y de Cooperación-Agencia Española de Cooperación Internacional para el Desarrollo (predoctoral scholarship to R.E.G.-T.) and the Ministerio de Economía y Competitividad through the Severo Ochoa Program for Centers of Excellence in R\&D 2016-2019 (SEV-2015-0533) and 2020-2023 (CEX2019-000902-S). The Article Processing Charge was financed by Ajuts de la Universitat de Barcelona per publicar en accés obert.

Acknowledgments: We thank Montse Amenós for help in image capturing and processing, Katharina Göttmann and Víctor Campos for the revision of English usage, the Confocal Microscopy Service of the Centre for Research in Agricultural Genomics (CRAG), the Advanced Optic Microscopy Unit of the Scientific and Technological Centers of the University of Barcelona (Faculty of Biology) 
and the Servei de Camps Experimentals de la Universitat de Barcelona and the Plant Growth Facility of CRAG.

Conflicts of Interest: The authors declare no conflict of interest. The funders had no role in the design of the study; in the collection, analyses, or interpretation of data; in the writing of the manuscript, or in the decision to publish the results.

\section{References}

1. Burg, J.S.; Espenshade, P.J. Regulation of HMG-CoA reductase in mammals and yeast. Prog. Lipid Res. 2011, 50, 403-410. [CrossRef] [PubMed]

2. Gutensohn, M.; Nagegowda, D.A.; Dudareva, N. Involvement of compartmentalization in monoterpene and sesquiterpene biosynthesis in plants. In Isoprenoid Synthesis in Plants and Microorganisms: New Concepts and Experimental Approaches; Springer: New York, NY, USA, 2013; pp. 155-169. ISBN 9781461440635.

3. Rodríguez-Concepción, M.; Boronat, A. Breaking new ground in the regulation of the early steps of plant isoprenoid biosynthesis. Curr. Opin. Plant Biol. 2015, 25, 17-22. [CrossRef] [PubMed]

4. Kutchan, T.M.; Gershenzon, J.; Moller, B.L.; Gang, D.R. Natural products. In Biochemistry and Molecular Biology of Plants; Buchanan, B.B., Gruissem, W., Jones, R.L., Eds.; Wiley Blackwell: Chichester, UK; Hoboken, NJ, USA, 2015; pp. 1132-1206. ISBN 9780470714218.

5. Lumbreras, V.; Campos, N.; Boronat, A. The use of an alternative promoter in the Arabidopsis thaliana HMG1 gene generates an mRNA that encodes a novel 3-hydroxy-3-methylglutaryl coenzyme A reductase isoform with an extended N-terminal region. Plant J. 1995, 8, 541-549. [CrossRef] [PubMed]

6. NCBI Genome Browser. Available online: https:/ /www.ncbi.nlm.nih.gov/genome/browse (accessed on 9 July 2021).

7. Enjuto, M.; Balcells, L.; Campos, N.; Caelles, C.; Arro, M.; Boronat, A. Arabidopsis thaliana contains two differentially expressed 3-hydroxy-3-methylglutaryl-CoA reductase genes, which encode microsomal forms of the enzyme. Proc. Natl. Acad. Sci USA 1994, 91, 927-931. [CrossRef] [PubMed]

8. Chappell, J. The Biochemistry and Molecular Biology of Isoprenoid Metabolism. Plant Physiol. 1995, 107, 1-6. [CrossRef]

9. Mo, C.; Bard, M. A systematic study of yeast sterol biosynthetic protein-protein interactions using the split-ubiquitin system. Biochim. Biophys. Acta 2005, 1737, 152-160. [CrossRef]

10. Mialoundama, A.S.; Jadid, N.; Brunel, J.; Di Pascoli, T.; Heintz, D.; Erhardt, M.; Mutterer, J.; Bergdoll, M.; Ayoub, D.; Van Dorsselaer, A.; et al. Arabidopsis ERG28 tethers the sterol C4-demethylation complex to prevent accumulation of a biosynthetic intermediate that interferes with polar auxin transport. Plant Cell 2013, 25, 4879-4893. [CrossRef]

11. Gachotte, D.; Eckstein, J.; Barbuch, R.; Hughes, T.; Roberts, C.; Bard, M. A novel gene conserved from yeast to humans is involved in sterol biosynthesis. J. Lipid Res. 2001, 42, 150-154. [CrossRef]

12. Campos, N.; Boronat, A. Targeting and topology in the membrane of plant 3-hydroxy-3-methylglutaryl coenzyme A reductase. Plant Cell 1995, 7, 2163-2174. [CrossRef]

13. Basson, M.E.; Thorsness, M.; Finer-Moore, J.; Stroud, R.M.; Rine, J. Structural and functional conservation between yeast and human 3-hydroxy-3-methylglutaryl coenzyme A reductases, the rate-limiting enzyme of sterol biosynthesis. Mol. Cell. Biol. 1988, 8, 3797-3808. [CrossRef]

14. Liscum, L.; Finer-Moore, J.; Stroud, R.M.; Luskey, K.L.; Brown, M.S.; Goldstein, J.L. Domain structure of 3-hydroxy-3methylglutaryl coenzyme A reductase, a glycoprotein of the endoplasmic reticulum. J. Biol. Chem. 1985, 260, 522-530. [CrossRef]

15. Olender, E.; Simon, R. The intracellular targeting and membrane topology of 3-hydroxy-3-methylglutaryl-CoA reductase. J. Biol. Chem. 1992, 267, 4223-4235. [CrossRef]

16. Profant, D.A.; Roberts, C.J.; Wright, R.L. Mutational analysis of the karmellae-inducing signal in Hmg1p, a yeast HMG-CoA reductase isozyme. Yeast 2000, 16, 811-827. [CrossRef]

17. Campos, N.; Palau, J.; Zwieb, C. Diversity of 7 SL RNA from the signal recognition particle of maize endosperm. Nucleic Acids Res. 1989, 17, 1573-1588. [CrossRef]

18. Leivar, P.; González, V.M.; Castel, S.; Trelease, R.N.; López-Iglesias, C.; Arró, M.; Boronat, A.; Campos, N.; Ferrer, A.; Fernàndez-Busquets, X. Subcellular localization of Arabidopsis 3-hydroxy-3-methylglutaryl-coenzyme A reductase. Plant Physiol. 2005, 137, 57-69. [CrossRef] [PubMed]

19. Ferrero, S.; Grados-Torrez, R.E.; Leivar, P.; Antolín-Llovera, M.; López-Iglesias, C.; Cortadellas, N.; Ferrer, J.C.; Campos, N. Proliferation and morphogenesis of the endoplasmic reticulum driven by the membrane domain of 3-hydroxy-3-methylglutaryl coenzyme A reductase in plant cells. Plant Physiol. 2015, 168, 899-914. [CrossRef] [PubMed]

20. Jingami, H.; Brown, M.S.; Goldstein, J.L.; Anderson, R.G.; Luskey, K.L. Partial deletion of membrane-bound domain of 3hydroxy-3-methylglutaryl coenzyme A reductase eliminates sterol-enhanced degradation and prevents formation of crystalloid endoplasmic reticulum. J. Cell Biol. 1987, 104, 1693-1704. [CrossRef] [PubMed]

21. Wright, R.G.; Basson, M.D.; D'Ari, L.; Rine, J. Increased amounts of HMG-CoA reductase induce "karmellae": A proliferation of stacked membrane pairs surrounding the yeast nucleus. J. Cell Biol. 1988, 107, 101-114. [CrossRef] [PubMed]

22. Sandor, A.; Fricker, M.D.; Kriechbaumer, V.; Sweetlove, L.J. IntEResting structures: Formation and applications of organized smooth endoplasmic reticulum in plant cells. Plant Physiol. 2020, 185, 550-561. [CrossRef] 
23. Chin, D.J.; Luskey, K.L.; Anderson, R.G.; Faust, J.R.; Goldstein, J.L.; Brown, M.S. Appearance of crystalloid endoplasmic reticulum in compactin-resistant Chinese hamster cells with a 500-fold increase in 3-hydroxy-3-methylglutaryl-coenzyme A reductase. Proc. Natl. Acad. Sci. 1982, 79, 1185-1189. [CrossRef]

24. Eymé, M.J. Infrastructure des cellules nectarigènes de Diplotaxis erucoides D. C., Helleborus niger L. et H. fetidus L. Comptes Rendus des Séances l'Académie des Sci. Ser. D 1996, 262, 1629-1632.

25. Eymé, M.J.; Le Blanc, M. Contribution à l'étude inframicroscopique d'inclusions cytoplasmatiques présentes dans les ovules de Ficaria et dans les nectaries d'Helleborus. Comptes Rendus des Séances l'Académie des Sci. Ser. D 1963, 256, 4958-4959.

26. Eymé, J. Nouvelles observations sur l'infrastructure des tissus nectarigènes floraux. Le Bot. (serie L) 1967, 50, 169-183.

27. Bassot, J.M. Une forme microtubulaire et paracristalline de reticulum endoplasmique dans les photocytes des annelides polynoinæ. J. Cell Biol. 1966, 31, 135-158. [CrossRef] [PubMed]

28. Wooding, F.B.P. Endoplasmic reticulum aggregates of ordered structure. Planta 1967, 76, 205-208. [CrossRef] [PubMed]

29. Christensen, A.K. The fine structure of testicular interstitial cells in guinea pigs. J. Cell Biol. 1965, 26, 911-935. [CrossRef] [PubMed]

30. Christensen, A.K.; Fawcett, D.W. The normal fine structure of opossum testicular interstitial cells. J. Cell Biol. 1961, 9, 653-670. [CrossRef]

31. Orrenius, S.; Ericsson, J.L.E.; Ernster, L. Phenobarbital-induced synthesis of the microsomal drug-metabolizing enzyme system and its relationship to the proliferation of endoplasmic membranes. J. Cell Biol. 1965, 25, 627-639. [CrossRef]

32. Jones, A.L.; Fawcett, D.W. Hypertrophy of the agranular endoplasmic reticulum in hamster liver induced by phenobarbital (with a review on the functions of this organelle in liver). J. Histochem. Cytochem. 1966, 14, 215-232. [CrossRef]

33. Franke, W.W.; Scheer, U. Some structural differentiations in the HeLa cell: Heavy bodies annulate lamellae and cotte de maillet endoplasmic reticulum. Cytobiologie 1971, 4, 317-329.

34. Black, V.H. The development of smooth-surfaced endoplasmic reticulum in adrenal cortical cells of fetal guinea pigs. Am. J. Anat. 1972, 135, 381-417. [CrossRef]

35. Barton, B.R.; Hertig, A.T. Ultrastructure of quiescent oocytes of Cebus albifrons. J. Anat. 1975, 120, 227-238. [PubMed]

36. Davidowitz, J.; Philips, G.H.; Pachter, B.R.; Breinin, G.M. Particle-free and glycogen-bearing double membrane arrays in extraocular muscle of rabbit. Am. J. Pathol. 1975, 78, 191-198.

37. Grimley, P.M.; Schaff, Z. Significance of tubuloreticular inclusions in the pathobiology of human diseases. Pathobiol. Annu. 1976, 6, 221-257.

38. Schaff, Z.; Lapis, K.; Grimley, P.M. Undulating membraneous structures associated with the endoplasmic reticulum in tumour cells. Int. J. Cancer 1976, 18, 697-702. [CrossRef] [PubMed]

39. Linder, J.C.; Staehelin, A. The membrane lattice: A novel organelle of the trypanosomatid flagellate Leptomonas collosoma. J. Ultrastruct. Res. 1980, 72, 200-205. [CrossRef]

40. Yamamoto, A.; Otsu, H.; Yoshimori, T.; Maeda, N.; Mikoshiba, K.; Tashiro, Y. Stacks of flattened smooth endoplasmic reticulum highly enriched in inositol 1,4,5-trisphosphate( $\left.\operatorname{InsP}_{3}\right)$ receptor in mouse cerebellar Purkinje cells. Cell Struct. Funct. 1991, 16, 419-432. [CrossRef]

41. Karnaky, K.J.; Lau, K.R.; Garretson, L.T.; Schultz, S.G. Seasonal variations in the fine structure of the Necturus maculosus urinary bladder epithelium: Low transporters and high transporters. Am. J. Anat. 1984, 171, 227-242. [CrossRef] [PubMed]

42. Kerr, J.B.; Weiss, M. Spontaneous or experimentally induced formation of a special zone in the adrenal cortex of the adult brush-tailed possum(Trichosurus vulpecula). Am. J. Anat. 1991, 190, 101-117. [CrossRef] [PubMed]

43. Wolf, K.W.; Motzko, D. Paracrystalline endoplasmic reticulum is typical of gametogenesis in Hemiptera species. J. Struct. Biol. 1995, 114, 105-114. [CrossRef]

44. Yamamoto, A.; Masaki, R.; Tashiro, Y. Formation of crystalloid endoplasmic reticulum in COS cells upon overexpression of microsomal aldehyde dehydrogenase by cDNA transfection. J. Cell Sci. 1996, 109, 1727-1738. [CrossRef] [PubMed]

45. Snapp, E.; Hegde, R.; Francolini, M.; Lombardo, F.; Colombo, S.; Pedrazzini, E.; Borgese, N.; Lippincott-Schwartz, J. Formation of stacked ER cisternae by low affinity protein interactions. J. Cell Biol. 2003, 163, 257-269. [CrossRef] [PubMed]

46. Almsherqi, Z.A.; Kohlwein, S.D.; Deng, Y. Cubic membranes: A legend beyond the Flatland* of cell membrane organization. J. Cell Biol. 2006, 173, 839-844. [CrossRef]

47. Almsherqi, Z.A.; Landh, T.; Kohlwein, S.D.; Deng, Y. Chapter 6: Cubic membranes the missing dimension of cell membrane organization. Int. Rev. cell Mol. Biol. 2009, 274, 275-342. [CrossRef] [PubMed]

48. Leivar, P.; Antolín-Llovera, M.; Ferrero, S.; Closa, M.; Arró, M.; Ferrer, A.; Boronat, A.; Campos, N. Multilevel control of Arabidopsis 3-hydroxy-3-methylglutaryl coenzyme A reductase by protein phosphatase 2A. Plant Cell 2011, 23, 1494-1511. [CrossRef]

49. Westrate, L.; Lee, J.; Prinz, W.; Voeltz, G. Form follows function: The importance of endoplasmic reticulum shape. Annu. Rev. Biochem. 2015, 84, 791-811. [CrossRef] [PubMed]

50. Hawes, C.; Kiviniemi, P.; Kriechbaumer, V. The endoplasmic reticulum: A dynamic and well-connected organelle. J. Integr. Plant Biol. 2015, 57, 50-62. [CrossRef]

51. Nishikawa, S.; Hirata, A.; Nakano, A. Inhibition of endoplasmic reticulum (ER)-to-Golgi transport induces relocalization of binding protein (BiP) within the ER to form the BiP bodies. Mol. Biol. Cell 1994, 5, 1129-1143. [CrossRef]

52. Bergmann, J.E.; Fusco, P.J. The G protein of vesicular stomatitis virus has free access into and egress from the smooth endoplasmic reticulum of UT-1 cells. J. Cell Biol. 1990, 110, 625-635. [CrossRef] 
53. Anderson, R.; Orci, L.; Brown, M.; Garcia-Segura, L.; Goldstein, J. Ultrastructural analysis of crystalloid endoplasmic reticulum in UT-1 cells and its disappearance in response to cholesterol. J. Cell Sci. 1983, 63, 1-20. [CrossRef] [PubMed]

54. Hurbain, I.; Sachse, M. The future is cold: Cryo-preparation methods for transmission electron microscopy of cells. Biol. Cell 2011, 103, 405-420. [CrossRef]

55. Ebersold, H.R.; Cordier, J.-L. Bacterial mesosomes: Method dependent artifacts. Arch. Microbiol. 1981, 130, 19-22. [CrossRef]

56. Higgins, M.L.; Tsien, H.C.; Daneo-Moore, L. Organization of mesosomes in fixed and unfixed cells. J. Bacteriol. 1976, 127, 1519-1523. [CrossRef]

57. Silva, M.; Sousa, J.; Polónia, J.; Macedo, M.; Parente, A.M. Bacterial mesosomes: Real structures of artifacts? Biochim. et Biophys. Acta (BBA)-Biomembr. 1976, 443, 92-105. [CrossRef]

58. Chandler, D. Comparison of quick-frozen and chemically fixed sea-urchin eggs: Structural evidence that cortical granule exocytosis is preceded by a local increase in membrane mobility. J. Cell Sci. 1984, 72, 23-36. [CrossRef] [PubMed]

59. Murk, J.L.A.N.; Posthuma, G.; Koster, A.; Geuze, H.J.; Verkleij, A.J.; Kleijmeer, M.J.; Humbel, B.M. Influence of aldehyde fixation on the morphology of endosomes and lysosomes: Quantitative analysis and electron tomography. J. Microsc. 2003, 212, 81-90. [CrossRef] [PubMed]

60. Orci, L.; Brown, M.S.; Goldstein, J.L.; Garcia-Segura, L.; Anderson, R.G. Increase in membrane cholesterol: A possible trigger for degradation of HMG-CoA reductase and crystalloid endoplasmic reticulum in UT-1 cells. Cell 1984, 36, 835-845. [CrossRef]

61. Kochevar, D.; Anderson, R. Purified crystalloid endoplasmic reticulum from UT-1 cells contains multiple proteins in addition to 3-hydroxy-3-methylglutaryl coenzyme A reductase. J. Biol. Chem. 1987, 262, 10321-10326. [CrossRef]

62. Zacharias, D.A.; Violin, J.D.; Newton, A.C.; Tsien, R.Y. Partitioning of lipid-modified monomeric GFPs into membrane microdomains of live cells. Science 2002, 296, 913-916. [CrossRef] [PubMed]

63. Istvan, E.S.; Palnitkar, M.; Buchanan, S.K.; Deisenhofer, J. Crystal structure of the catalytic portion of human HMG-CoA reductase: Insights into regulation of activity and catalysis. EMBO J. 2000, 19, 819-830. [CrossRef] [PubMed]

64. Murashige, T.; Skoog, F. A revised medium for rapid growth and bio-assays with tobacco tissue cultures. Physiol. Plant. 1962, 15, 473-497. [CrossRef]

65. Batoko, H.; Zheng, H.-Q.; Hawes, C.; Moore, I. A rab1 GTPase is required for transport between the endoplasmic reticulum and Golgi apparatus and for normal Golgi movement in plants. Plant Cell 2000, 12, 2201-2217. [CrossRef] [PubMed]

66. Van Der Hoorn, R.A.L.; Laurent, F.; Roth, R.; de Wit, P. Agroinfiltration is a versatile tool that facilitates comparative analyses of Avr9/Cf-9-induced and Avr4/Cf-4-induced necrosis. Mol. Plant-Microbe Interactions 2000, 13, 439-446. [CrossRef] [PubMed]

67. Koncz, C.; Schell, J. The promoter of TL-DNA gene 5 controls the tissue-specific expression of chimaeric genes carried by a novel type of Agrobacterium binary vector. Mol. Genet. Genom. 1986, 204, 383-396. [CrossRef]

68. Sauer, M.; Paciorek, T.; Benková, E.; Friml, J. Immunocytochemical techniques for whole-mount in situ protein localization in plants. Nat. Protoc. 2006, 1, 98-103. [CrossRef] [PubMed] 